\title{
Ornamentasi Vokal pada Tarsul Kutai Kartanegara
}

\author{
Vocal Ornamentation of "Tarsul" Kutai Kartanegara
}

Zamrud Whidas Pratama*, Program Studi Etnomusikologi, Fakultas Ilmu Budaya, Universitas Mulawarman. Email: zamrud.whidas@fib.unmul.ac.id

Aris Setyoko, Program Studi Etnomusikologi, Fakultas Ilmu Budaya, Universitas Mulawarman. Email: aris.setyoko@fib.unmul.ac.id

Fikri Yassar Arozaq, Program Studi Etnomusikologi, Fakultas Ilmu Budaya, Universitas Mulawarman. Email: fikriya90@gmail.com

\author{
Received: \\ 3 Maret 2021 \\ Accepted: \\ 30 Maret 2021 \\ Published: \\ 3 April 2021
}

Keywords:

tarsul, ornaments, vocal.

Kata kunci:

tarsul, ornamen, vokal.

\begin{abstract}
:
One form of singing or chanting spread through cultural needs is a traditional song originating from Kutai Kartanegara called tarsul. This study aimed to obtain data about what vocal ornaments are contained in the Kutai tarsul. The theory used in this research is the theory of music presentation forms, ornamentation, and western music vocal techniques. A qualitative descriptive study was chosen by prioritizing the musicology approach. The data was collected by (1) literature study, (2) observation, (3) interviews, (4) documentation. The stages in analyzing data are (1) data reduction, (2) data presentation, (3) historiography writing, and (4) conclusions. Data clarification was again carried out using data triangulation techniques. The results showed two kinds of tarsul rhythms commonly used by petarsul, namely tarsul with one rhythm (low) and tarsul with a rhythm of two (high). In Kutai Kartanegara's tarsul, there are several ornaments. Many melismatic ornaments are found at the end of the melody of each part of the tarsul sentence. There are three forms of melismatic ornamentation named for easy classification: melismatic ornament A, melismatic ornament B, and melismatic ornament C. Apart from melismatic ornamentation, there is symbolic ornamentation on tarsul, namely trill ornamentation. Next is the morden ornamentation. More specifically, lower mordent ornamentation was found. Lastly is the use of grupetto ornamentation. From the transcription and tarsul analysis of rhythm patterns 1 and 2, it was found groupetto reverse turn ornamentation.
\end{abstract}

\begin{abstract}
Abstrak:
Salah satu bentuk nyanyian atau senandung yang di sebarkan melalui kebutuhan budaya adalah nyanyian tradisional yang berasal dari Kutai Kartanegara yang disebut tarsul. Tujuan penelitian ini adalah untuk memperoleh data tentang bagaimana ornamen vokal apa saja yang terdapat dalam tarsul Kutai. Teori yang digunakan dalam penelitian ini adalah teori bentuk penyajian musik, ornamentasi, dan teknik vokal musik barat. Untuk mengkajinya dipilih penelitian deskriptif kualitatif dengan mengutamakan pendekatan musikologi. Pengumpulan data dilakukan dengan cara (1) studi kepustakaan, (2) observasi, (3) wawancara, (4) dokumentasi. Tahap-tahap dalam menganalisis data dengan (1) reduksi data, (2) penyajian data, (3) penulisan historiografi, and (4) kesimpulan. Klarifikasi data kembali dilakukan menggunakan teknik triangulasi data. Hasil penelitian menunjukkan bahwa terdapat dua macam irama tarsul yang biasa digunakan oleh para petarsul, yaitu tarsul dengan irama satu (rendah) dan tarsul dengan irama dua (tinggi). Dalam tarsul Kutai Kartanegara terdapat beberapa ornamen. Ornamen melismatis banyak terdapat pada akhir melodi setiap bagian kalimat tarsul. Terdapat tiga bentuk ornamentasi melismatis yang diberi nama agar mudah dalam
\end{abstract}


mengelompokkannya, yaitu ornamen melismatis A, ornamen melismatis B, dan ornamen melismatis C. Selain ormantasi melismatis, terdapat ornamentasi simbol pada tarsul, yaitu ornamentasi trill. Berikutnya terdapat ornamentasi morden. Lebih spesifik lagi, ditemukan ornamentasi lower mordent. Terakhir adalah penggunaan ornamentasi grupetto. Dari hasil transkripsi dan analisis tarsul pola irama 1 dan 2 ditemukan ornamentasi grupetto reverse turn.

\section{Citation:}

Pratama, Z. W., Setyoko, A., \& Arozaq, F. Y. (2021). Ornamentasi Vokal pada Tarsul Kutai Kartanegara. Jurnal Mebang: Kajian Budaya Musik dan Pendidikan Musik, 1(1), 25-34. http://jurnal.fib-unmul.id/index.php/mebang/article/view/3

\section{Pendahuluan}

Musik vokal adalah musik yang bersumber dari suara manusia, bisa dimainkan oleh seorang penyanyi atau sekelompok orang. Jika dinyanyikan perorangan disebut solo, sedangkan secara bersama disebut paduan suara. Pemahaman di atas adalah pemahaman dari sisi terminologi musik barat. Saat manusia mengeluarkan suara dari mulut disertai dengan teknik vokal sehingga menimbulkan suara yang merdu maka itu disebut dengan bernyanyi. Tetapi perlu dipahami bahwa hal ini membatasi diri kita sebagai manusia yang berbudaya di mana mengeluarkan suara dari mulut untuk mengisi waktu luang, menidurkan anak, adalah nyanyian-nyanyian atau senandung-senandung yang memiliki makna dan keindahan tersendiri dari setiap kebudayaan.

Salah satu bentuk nyanyian atau senandung yang di sebarkan melalui kebutuhan budaya adalah nyanyian tradisional yang berasal dari Suku Kutai Kartanegara yang disebut tarsul. Tarsul atau tarsulan adalah salah satu seni bernyanyi dari suku Kutai yang sampai sekarang masih ada di dalam masyarakat. Tarsul tetap eksis dan berkembang di masyarakat suku Kutai karena berkaitan dengan kebutuhan budaya yang masih digunakan oleh masyarakat Kutai yang masih di penyajian dalam acara-acara tertentu. Tradisi tarsul mulai berkembang di Kutai Kartanegara diawali dengan masuknya agama Islam yang dibawa dari Arab melalui pedagang Gujarat. Selain membawa pengaruh agama Islam di Kerajaan Kutai Kartanegara pengaruh dalam bidang seni. Seni yang dibawa oleh para pedagang yaitu seni sastra yang berbentuk syair. Hal inilah yang membuat salah satu bangsawan dari Kerajaan Kutai Kartanegara yang ingin mengaitkan budaya yang datang dengan budaya suku Kutai Kartanegara. Oleh karena itu lahirlah kesenian tarsul di mana syair yang memiliki tema tertentu diberi dengan melodi yang khas.

Tarsul merupakan tradisi lisan yang sudah berkembang secara turun-temurun pada masyarakat suku Kutai. Awalnya tarsul adalah seni yang boleh dinyanyikan oleh para bangsawan Kerajaan Kutai khususnya tarsulan berkatam Al-Qur'an yang di nyanyikan oleh para penarsul. Para penarsul dalam menyanyikan melodi dan syair tarsul dengan cara menghafal. Namun dalam perkembangannya, karena merasa kesulitan untuk menghafal, penarsul mulai menggunakan naskah yang berisi syair tarsul. Penelitian ini bertujuan untuk meneliti ornamentasi pada nyanyian tarsul di Suku Kutai Kartanegara. Ornamentasi merupakan hiasan untuk memperindah melodi dalam sebuah lagu. Terdapat beberapa ornamentasi dalam musik barat, yaitu ornamentasi melismatis dan ornamentasi simbol. Ornamentasi melismatis adalah ornamen yang ditulis secara langsung pada partitur dan dinyanyikan sesuai dengan notasi yang ada. Berikutnya, ornamentasi simbol yaitu ornamentasi 
yang dipraktikkan atau dinyanyikan sesuai dengan simbol yang ada. Ornamentasi simbol meliputi Trill, Grupetto, Accaciaccatura, Appoggiatura, Morden, dan Arpeggio.

Ornamen Trill dimainkan/dinyanyikan secara bergantian dengan nada terdekat atau nada tetangga. Ornamen ini dikenal dengan istilah ornamen shake (kocok) dalam memainkannya (Pratama, 2020, p. 99). Lambang dari ornamen ini dalam musik barat adalah of yang terletak di atas notasi yang diinginkan.

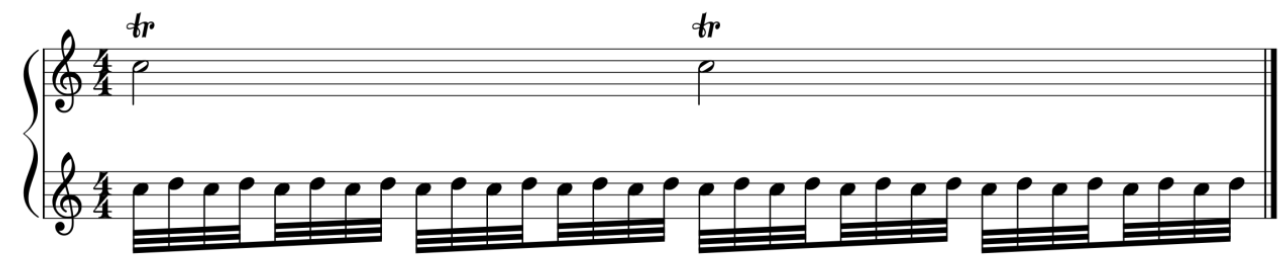

Notasi 1. Trill (Pratama, 2020)

Selanjutnya adalah ornamen Grupetto. Ornamen ini dilambangkan dengan $\boldsymbol{\curvearrowright}$ (reverse turn) dan $\bigcirc$ (turn). Setiap lambang Grupetto memiliki cara tersendiri dalam memainkannya. Berikut ini adalah notasi dari Grupetto reverse turn.

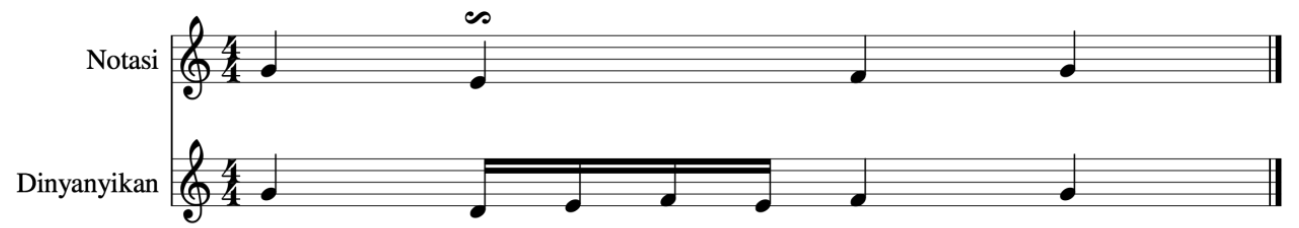

Notasi 2. Grupetto Reverse Turn (Pratama, 2020)

Cara menyanyikannya dengan memecah nada yang mendapatkan ornamen Grupetto menjadi empat nada yang melangkah mengelilingi nada tersebut. Selanjutnya adalah ornamen grupetto turn. Pratama (2020, p. 101) mengungkapkan bahwa cara menyanyikannya ornamen ini dimulai dari not di atas not dasar yang tertera. Lebih jelasnya perhatikan notasi di bawah ini.

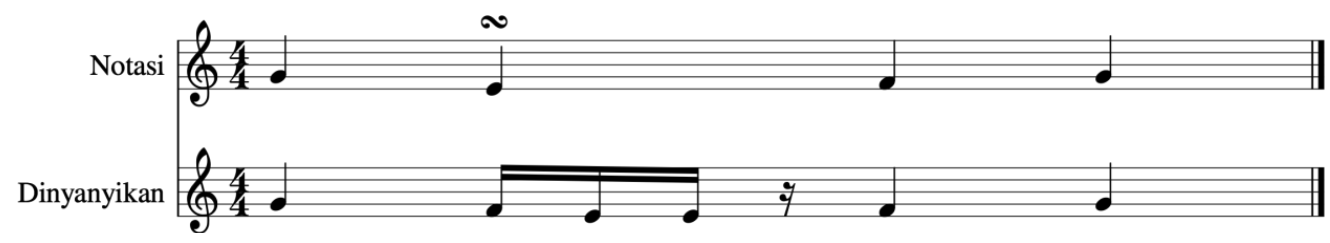

Notasi 3. Grupetto Turn (Pratama, 2020)

Selanjutnya menurut Marchesi (1970) morden terdiri atas sekelompok dua atau tiga notasi sebelum notasi utama. Kelompok melodi ini harus dinyanyikan dengan cepat. Menurut Pratama (2020, p. 105) menjelaskan Ornamen ini terdiri dari dua macam, yang pertama adalah pengertian notasi yang bergerak ke atas lalu kemudian kembali ke notasi asal (upper mordent) 
dituliskan dengan tanda $\boldsymbol{w}$, dan yang kedua adalah pergerakan notasi ke bawah, kemudian kembali lagi ke notasi awal (lower mordent) ditulis dengan tanda

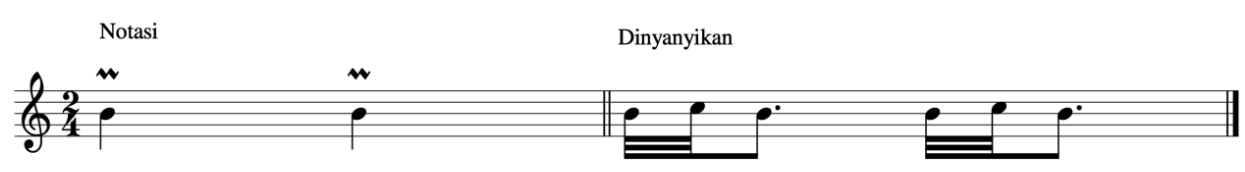

Notasi 4. Upper Mordent (Pratama, 2020)

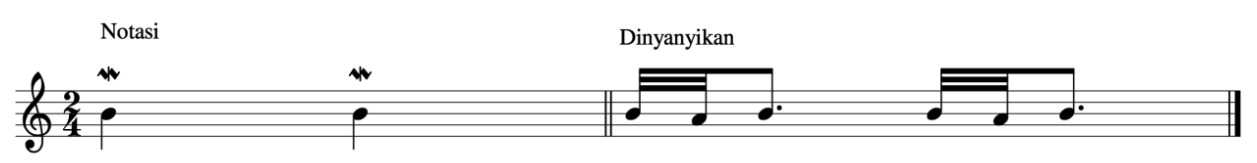

Notasi 5. Lower Mordent (Pratama, 2020)

Dengan adanya pendokumentasian budaya berupa transkripsi dalam bentuk notasi diharapkan tarsul dapat di pelajari oleh para akademisi musik di luar dari masyarakat di luar kebudayaan Kutai Kartanegara baik secara notasi maupun ornamentasinya.

\section{Metode}

Penelitian ini mengkaji tentang bagaimana bentuk penyajian, ornamentasi, dan teknik bernyanyi dalam kesenian tarsul Kutai Kartanegara. Untuk mengkajinya dipilih penelitian deskriptif kualitatif dengan mengutamakan pendekatan musikologi. Pemilihan kesenian tarsul sebagai subjek penelitian berkaitan dengan bagaimana penyajian tarsul biasa disajikan dan disaksikan oleh masyarakat Kutai Kartanegara. Selain itu ornamentasi apa saja yang terdapat dalam melodi tarsul sehingga menjadi suatu kesenian yang khas. Berhubungan dengan suatu kekhasan dalam kesenian pasti berhubungan dengan karakteristik bagaimana bunyi (sound) yang dihasilkan bila akan menyanyikan kesenian tarsul tersebut. Jenis penelitian ini termasuk dalam penelitian lapangan (field study), yaitu studi penelitian turun langsung ke lapangan. Pendekatan musikologi dipilih untuk mendeskripsikan musik untuk menentukan bentuk penyajian, ornamentasi dan teknik yang digunakan dalam tarsul Kutai Kartanegara mengaju pada perspektif keilmuan musik barat yang telah ada.

\section{Hasil dan Pembahasan}

\subsection{Transkripsi Tarsul Kutai Kartanegara}

Transkripsi adalah bentuk pengarsipan dalam bentuk tulisan yang dapat digunakan sebagai pedoman agar suatu kesenian musik tidak hilang. Hal ini di khawatirkan jika sebuah karya musik tidak memiliki tulisan akan terjadi kepunahan karena penuturnya sudah tidak ditemui lagi. Apabila dalam pemahaman notasi musik barat transkripsi dapat digunakan 
karena dapat sama persis menginterpretasi lagu tersebut. Berbeda dengan seni tradisi di mana interpretasi dalam bermusik lebih diutamakan. Oleh karena itu transkripsi hanya digunakan sebagai pengingat dalam menyanyikan karya musik khususnya musik tradisi. Tarsul merupakan seni tutur yang penyebarannya hanya dari penyebaran lisan. Tarsul belum memiliki dokumentasi tertulis yang dapat digunakan sebagai media belajar bagi akademisi ataupun praktisi seni yang ingin melantunkannya. Oleh sebab itu transkripsi dianggap penting sebagai dokumentasi tertulis yang dapat digunakan sebagai media belajar. Selain itu dapat digunakan untuk menganalisis ornamentasi, range nada dan frasering yang terdapat pada tarsul Kutai Kartanegara. Agar lebih mudah dalam menganalisis penulis memilih tarsul Kutai dengan tema syair perkawinan.

Transkripsi tarsul berdasarkan hasil wawancara bersama Achmad Fauzi pada tanggal 23 Juli 2020 adalah sebagai berikut.

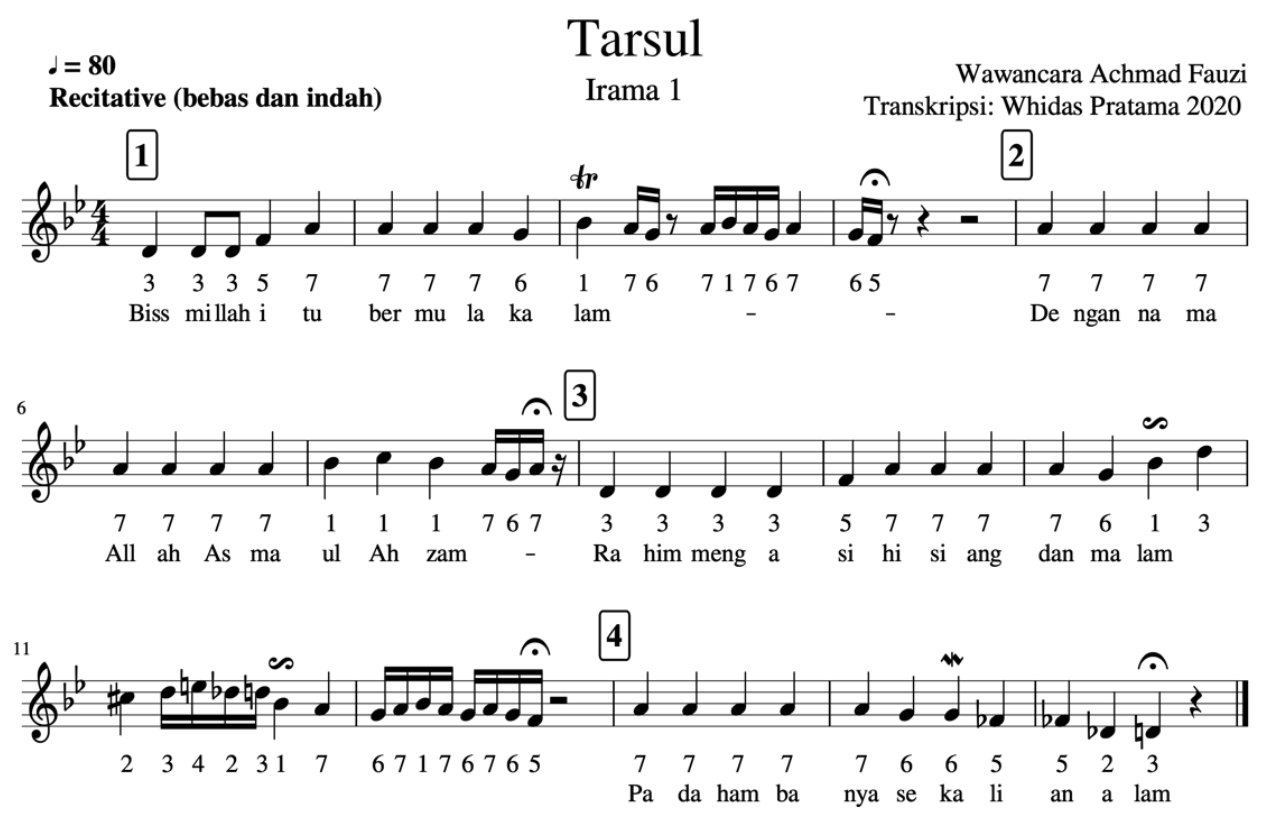

Notasi 6. Transkripsi Tarsul Irama 1 Hasil Wawancara Achmad Fauzi 

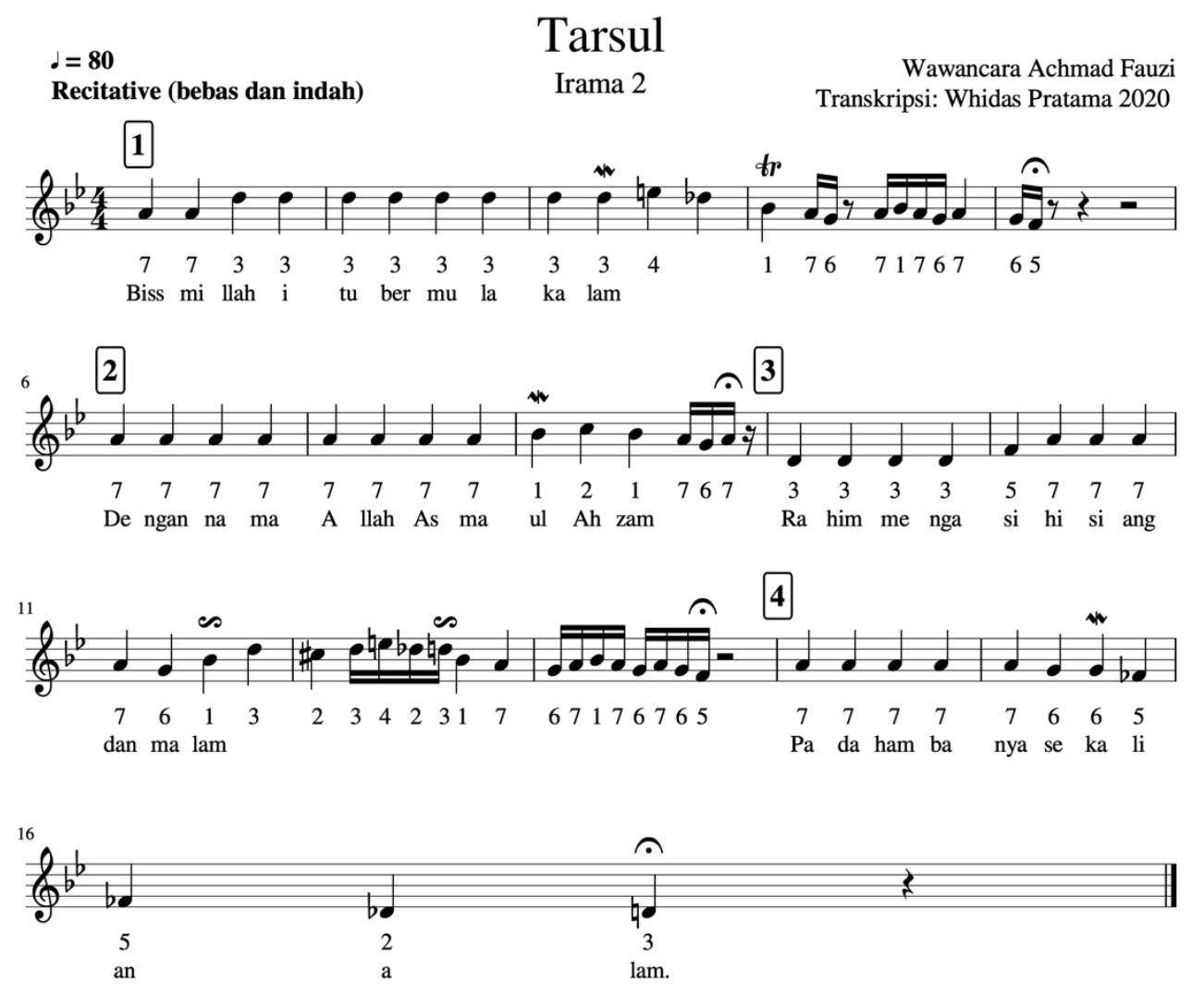

Notasi 7. Transkripsi Tarsul Irama 2 Hasil Wawancara Achmad Fauzi

Notasi transkripsi tarsul di atas adalah notasi transkripsi tarsul dengan irama satu dan irama dua. Terdapat dua macam irama tarsul yang biasa digunakan oleh para petarsul. Apabila tarsul dinyanyikan sendiri maka dipersilahkan untuk memilih irama mana yang akan dinyanyikan. Apabila akan dilantunkan oleh duet laki-laki dan perempuan maka dapat menggunakan ke dua macam irama tarsul tersebut yang membedakan dari tarsul irama satu dan dua alah starting poin atau habitus yang akan dicapai. Dalam satu nyanyian tarsul terdapat empat bagian melodi. Bagian dari setiap melodi merupakan empat bagian dari syair tarsul yang biasanya dinyanyikan. Oleh karena itu, penulis memberikan tanda pada transkripsi, yaitu penomoran yang menandakan nomor pada setiap bagian pada melodi tarsul. Berikut ini adalah contohnya.

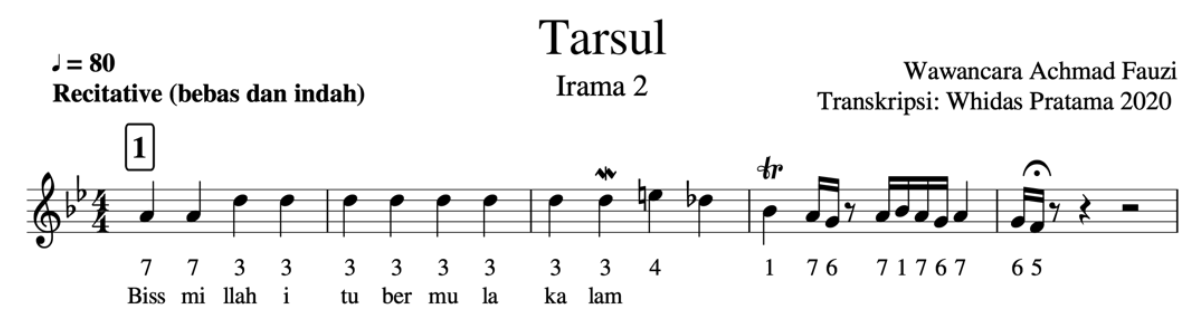

Notasi 8. Cuplikan Transkripsi Tarsul Irama 2 Hasil Wawancara Achmad Fauzi 
Pada bagian tersebut ditunjukkan dengan nomor 1, berarti bagian satu pada syair tarsul yang ditutup dengan tanda fermata yang menandakan bahwa melodi tersebut selesai dinyanyikan pada bagian satu.

\subsection{Ornamentasi Vokal Tarsul}

Ornamentasi merupakan hiasan untuk memperindah melodi dalam sebuah lagu. Dalam tarsul Kutai Kartanegara terdapat beberapa ornamen yang harus diperhatikan agar tarsul yang dilantunkan menjadi indah saat diperdengarkan. Berdasarkan analisis terdapat beberapa ornamen yaitu ornamen asli dalam lagu dan ornamen yang ditunjukkan dengan simbol notasi musik. Lebih jelasnya akan dibahas sebagai berikut.

\subsubsection{Ornamen Melismatis}

Tabel 1. Analisis Ornamen Melismatis

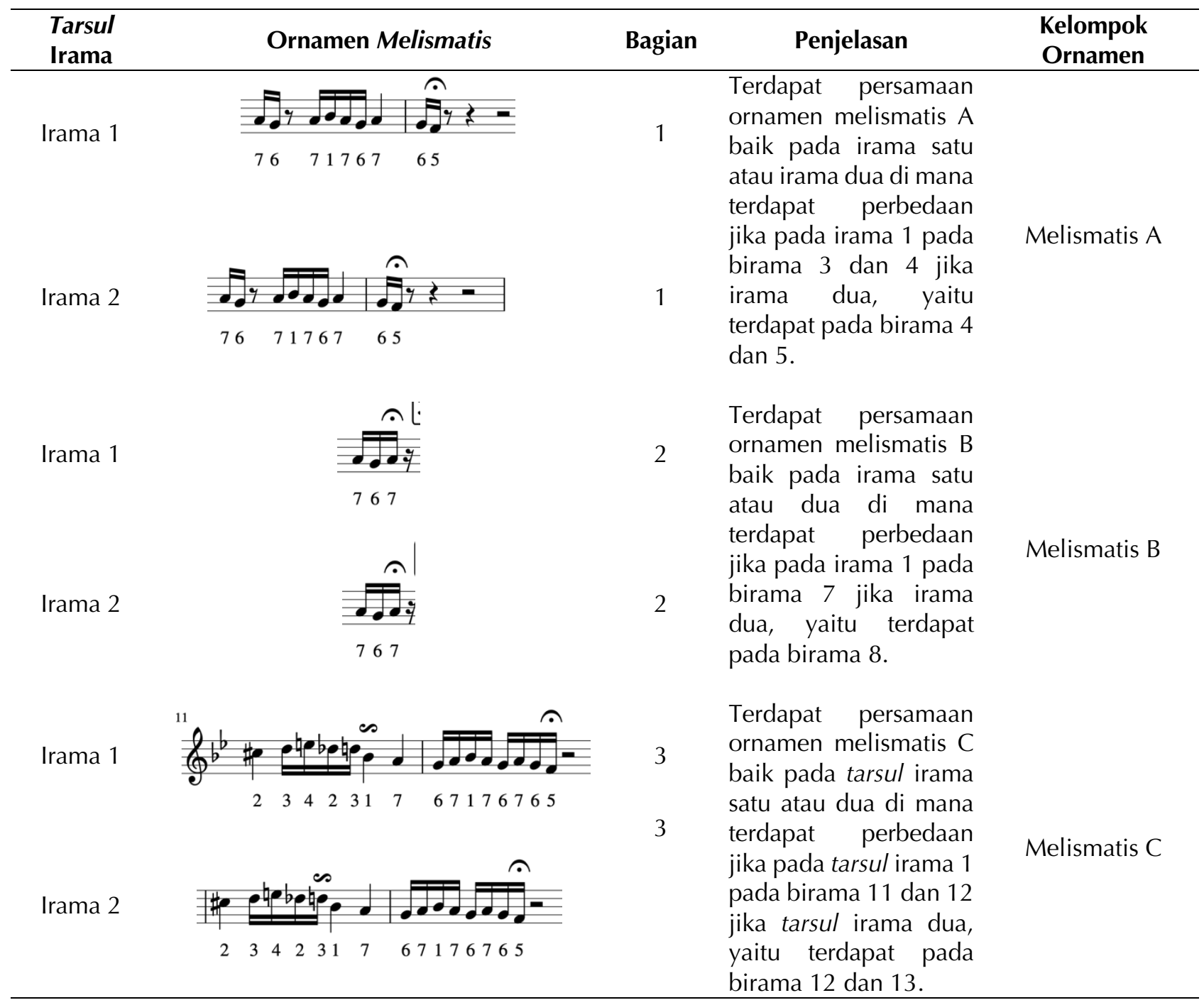


Dari hasil transkripsi dan analisis melismatis pada tarsul irama 1 dan irama 2, terdapat 3 bentuk ornamentasi melismatis yang diberikan nama agar mudah mengelompokkannya, yaitu ornamen Melismatis A, ornamen Melismatis B, dan ornamen Melismatis C di mana terdapat perbedaan pada peletakan ornamentasi Melismatis tersebut.

\subsubsection{Ornamentasi Simbol Trill}

Tabel 2. Analisis Ornamen Trill

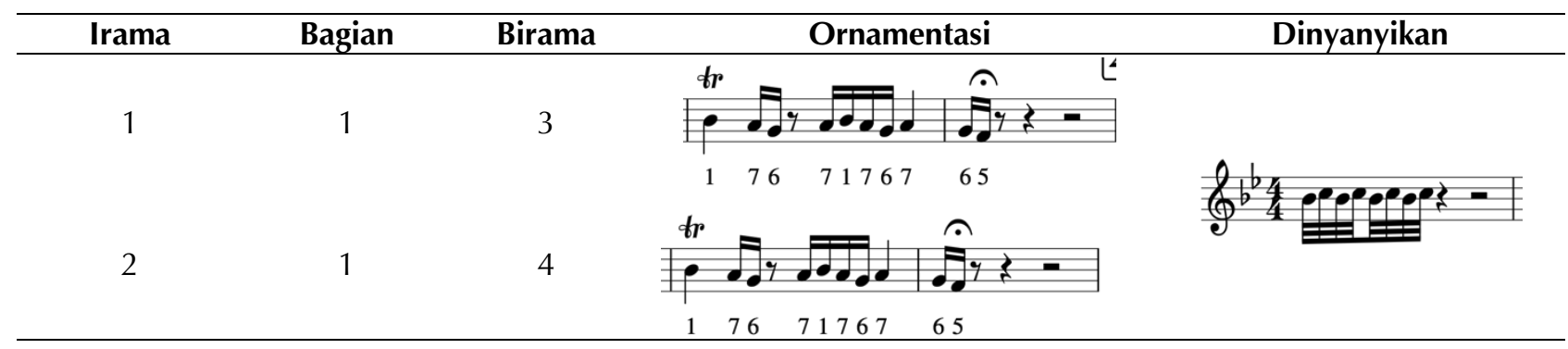

Dari hasil transkripsi pada irama tarsul 1 dan irama tarsul 2 terdapat penggunaan ornamentasi trill. Ornamentasi trill terdapat pada pola irama 1 dan 2 bagian 1 . Hanya peletakannya saja yang berbeda jika pada pola irama 1 terdapat pada birama 3, selanjutnya pada pola tarsul irama 2 pada birama 4. Ornamentasi berada pada nada b dengan harga nada 1/4. Ornamentasi trill ini digunakan untuk memberikan ornamen sebelum dinyanyikan melismatis yang sudah tertulis.

\subsubsection{Ornamentasi Simbol Mordent}

Tabel 3. Analisis Ornamen Mordent

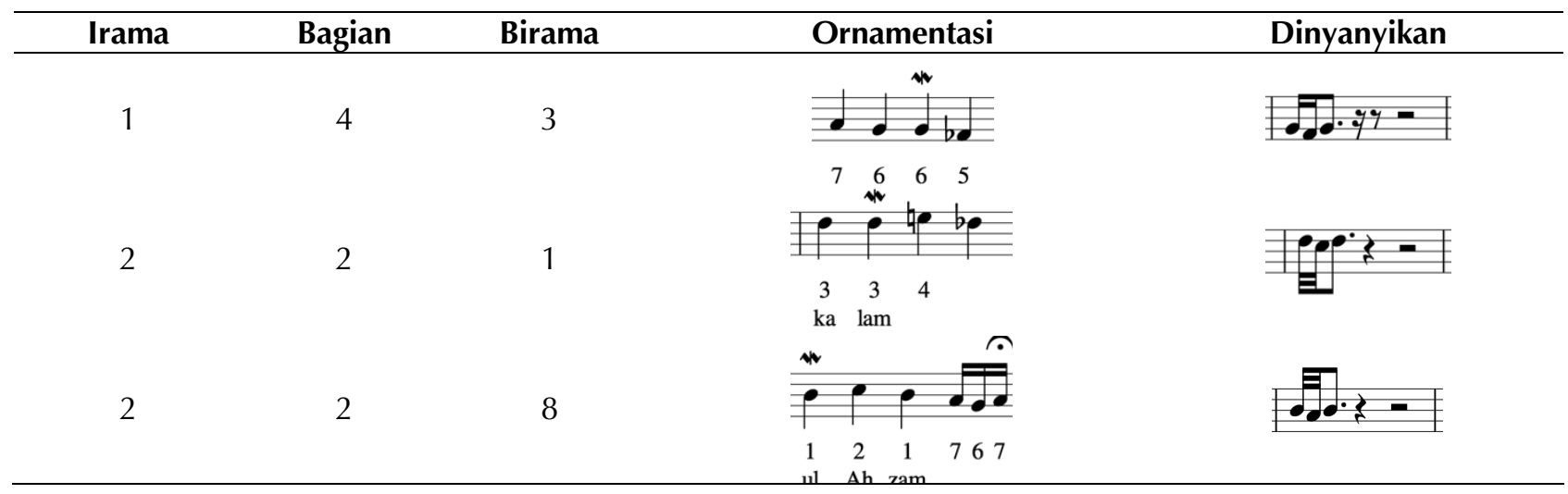

Dari hasil transkripsi dan analisis tarsul pola irama 1 dan 2 pada tabel di atas ditemukan ornamentasi lower mordent. Ornamentasi lower mordent terdapat pada pola irama 1 bagian 4 birama ke-3 pada nada $g$ dengan nilai nada 1/4. Selanjutnya terdapat pada pola irama 2 bagian 2 birama ke-1 pada nada $d^{\prime}$ dengan nilai nada 1/4. Terakhir lower mordent terdapat pada pola irama 2 bagian 2 birama ke-8 pada nada $b$ dengan nilai nada $1 / 4$. 


\subsubsection{Ornamentasi Grupeto}

Tabel 4. Analisis Ornamen Grupeto

\begin{tabular}{|c|c|c|c|c|}
\hline Irama & Bagian & Birama & Ornamentasi & Dinyanyikan \\
\hline 1 & 3 & 11 & 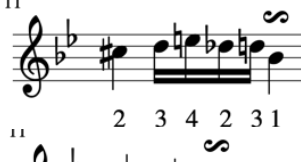 & mpos - \\
\hline 2 & 3 & 11 & $\begin{array}{ccccc}7 & 6 & 1 & \\
\text { dan } & \text { ma lam } & \end{array}$ & epe? \\
\hline 2 & 3 & 12 & 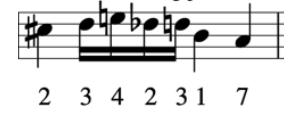 & Alpop?-1 \\
\hline
\end{tabular}

Dari hasil transkripsi dan analisis tarsul pola irama 1 dan 2 pada tabel di atas ditemukan ornamentasi Grupetto reverse turn. Penjelasannya Grupetto reverse turn terdapat pada pola irama 1 bagian 3 birama ke-11 pada nada b dengan nilai nada 1/4. Selanjutnya Grupetto reverse turn terdapat pada pola irama 2 bagian 3 birama ke-11 pada nada b dengan nilai nada $1 / 4$. Terakhir Grupetto reverse turn terdapat pada pola irama 2 bagian 3 birama ke-12 pada nada $b$ dengan nilai nada $1 / 4$.

\section{Simpulan}

Salah satu bentuk nyanyian atau senandung yang di sebarkan melalui kebutuhan budaya adalah nyanyian tradisional yang berasal dari Suku Kutai Kartanegara yang disebut tarsul. Tarsul Kutai Kartanegara adalah salah satu kesenian tutur yang terdapat di Kabupaten Kutai Kartanegara. Bentuk penyajian kesenian tarsul Kutai Kartanegara saat ini sudah sangat bervariasi dalam pertunjukannya mulai dari diiringi instrumen kibor, gambus dan ansambel band. Berdasarkan sejarahnya tarsul adalah salah satu seni tutur yang di lantunkan tanpa adanya iringan apa pun dalam melantunkannya. tarsul ini biasanya dinyanyikan secara solo atau sendirian dan juga dinyanyikan secara duet atau dua orang yaitu laki-laki dan perempuan tergantung pada syair yang dibawakannya. Pada masa sekarang pada akhirnya tarsul sudah mulai banyak digunakan dalam berbagai macam karya musik. Karya-karya musik tersebut di antaranya adalah musik tari, musik instrumental, ataupun musik-musik dengan garapan musik etnis. Terdapat dua macam irama tarsul yang biasa digunakan oleh para petarsul, yaitu tarsul dengan irama satu (rendah) dan tarsul dengan irama dua (tinggi). Ornamentasi merupakan hiasan untuk memperindah melodi dalam sebuah lagu. Dalam tarsul Kutai Kartanegara terdapat beberapa ornamen yang pertama adalah ornamen melismatis yang banyak terdapat pada akhir melodi setiap bagian kalimat tarsul. Terdapat 3 bentuk ornamentasi melismatis yang diberi nama agar mudah dalam mengelompokkannya, yaitu ornamen Melismatis A, ornamen Melismatis B, dan ornamen Melismatis C. Selain ornamentasi Melismatis terdapat ornamentasi simbol pada tarsul, yaitu ornamentasi trill. Ornamentasi trill terdapat pada pola irama 1 dan 2 
bagian 1. Hanya peletakannya saja yang berbeda jika pada pola irama 1 terdapat pada birama 3 , selanjutnya pada pola tarsul irama 2 pada birama 4. Ormaentasi Trill terdapat pada nada $b$ dengan harga nada 1/4. Ornamentasi Trill ini berdampingan dengan ornamentasi melismatis. Berikutnya terdapat ornamentasi Morden. Lebih spesifik lagi yaitu ditemukan ornamentasi lower mordent. Dari hasil transkripsi dan analisis tarsul pola irama 1 dan 2 ditemukan ornamentasi lower mordent terdapat pada pola irama 1 bagian 4 birama ke-3 pada nada $g$ dengan nilai nada $1 / 4$. Selanjutnya terdapat pada pola irama 2 bagian 2 birama ke-1 pada nada $d^{\prime}$ dengan nilai nada $1 / 4$. Terakhir lower mordent terdapat pada pola irama 2 bagian 2 birama ke-8 pada nada $b$ dengan nilai nada $1 / 4$. Terakhir adalah penggunaan ornamentasi Grupeto. Dari hasil transkripsi dan analisis tarsul pola irama 1 dan 2 pada tabel di atas ditemukan ornamentasi Grupetto reverse turn. Penjelasannya Grupetto reverse turn terdapat pada pola irama 1 bagian 3 birama ke-11 pada nada b dengan nilai nada 1/4. Selanjutnya Grupetto reverse turn terdapat pada pola irama 2 bagian 3 birama ke-11 pada nada b dengan nilai nada 1/4. Terakhir Grupetto reverse turn terdapat pada pola irama 2 bagian 3 birama ke-12 pada nada $b$ dengan nilai nada $1 / 4$.

\section{Referensi}

Ali, M. (2006). Teknik-Teknik Bernyanyi. Bandung: Sinar Baru.

Banoe, P. (2003). Kamus Musik. Yogyakarta: Kanisius.

Djelantik, A. A. M., Rahzen, T., \& Suryani, N. N. M. (1999). Estetika: Sebuah Pengantar. Bandung: Masyarakat Seni Pertunjukan Indonesia.

Hardjana, S. (1983). Estetika Musik. Jakarta: Depdikbud.

Jamalus, D. (1988). Pengajaran Musik Melalui Pengalaman Musik. Jakarta: Departemen Pendidikan dan Kebudayaan.

Kusumawati, H. (2004). Komposisi Dasar. Yogyakarta: Program Studi Seni Musik, Fakultas Bahasa dan Seni, Universitas Negeri Yogyakarta.

McKinney, J. C. (2005). The Diagnosis and Correction of Vocal Faults: A Manual for Teachers of Singing and for Choir Directors. Long Grove, IL: Waveland Press.

Mudjilah, H. S. (2004). Diktat Teori Musik Dasar. Yogyakarta: Universitas Negeri Yogyakarta. Oktara, B. (2011). Jago Teknik Vokal. Jakarta: Gramedia.

Poerwadarminta, W. J. S. (1989). Kamus Besar Bahasa Indonesia. Jakarta: Balai Pustaka.

Pratama, Z. W. (2020). Vokal: Teori dan Praktik. Samarinda: Mulawarman University Press.

Prier, K. E., \& Edmund, K. (2011). Kamus Musik. Yogyakarta: Pusat Musik Liturgi.

Salim, D. (2009). Psikologi musik. Yogyakarta: Best Publisher.

Sugiyono, P. D. (2008). Metode Penelitian Kuantitatif, Kualitatif, dan R\&D. Bandung: Alfabeta. Sumarjo, Y. (2000). Filsafat Seni. Bandung: Penerbit ITB.

Tambayong, Y. (1992). Ensiklopedia Musik Jilid II. Jakarta: Cipta Adi.

Ware, C. (1998). Basics of Vocal Pedagogy: The Foundations and Process of Singing. New York: McGraw-Hill.

\section{Daftar Narasumber/Informan}

1. Achmad Fauzi, (29 th), Praktisi Musik dan Guru Seni, wawancara pada 23 Juli 2020 di SMK N 2 Tenggarong, Samarinda, Kalimantan Timur. 